\title{
As dificuldades do parto domiciliar planejado no Brasil: Uma revisão sistemática
}

\author{
The difficulties of planned home birth in Brazil: A systematic review \\ Las dificuldades del parto domiciliario planificado en Brasil: Una revisión sistemática
}

Recebido: 26/05/2021 | Revisado: 04/06/2021 | Aceito: 15/06/2021 | Publicado: 29/06/2021

Priscila Braga Valinho
ORCID: https://orcid.org/0000-0003-1368-7238
Universidade do Estado do Rio de Janeiro, Brasil
E-mail: prisbraga.v@ hotmail.com
Marcele Zveiter
ORCID: https://orcid.org/0000-0001-6027-2276
Universidade do Estado do Rio de Janeiro, Brasil
E-mail: marcelezveiter@ hotmail.com
Ricardo José Oliveira Mouta
ORCID: https://orcid.org/0000-0002-1284-971X
Universidade do Estado do Rio de Janeiro, Brasil
E-mail:ricardomouta @ hotmail.com
Sabrina Lins Seibert
ORCID: https://orcid.org/0000-0003-1631-8980
Escola Nacional de Saúde Pública Sérgio Arouca, Brasil
E-mail:sabrinalinsseibert@gmail.com
Sérgio Corrêa Marques
ORCID: https://orcid.org/0000-0003-2597-4875
Universidade do Estado do Rio de Janeiro, Brasil
E-mail: scmarques2012@ gmail.com

\begin{abstract}
Resumo
Objetivo: descrever as dificuldades do parto domiciliar planejado no Brasil evidenciados na produção científica da enfermagem. Metodologia: Revisão sistemática utilizando os descritores Parto Domiciliar; Enfermagem Obstétrica e Cuidados de Enfermagem. O levantamento dos artigos foi feito em três bases de dados: Scientific Eletronic Library Online (SCiELO), Medical Literature Analysis and Retrievel System Online (Medline) e Literatura Latino-americana e do Caribe em Ciências da Saúde (LILACS), orientado pela questão norteadora: Quais são as dificuldades do parto domiciliar planejado no Brasil? Foram incluídos os estudos publicados a partir do ano de 2010 até março de 2021. Resultados: No total, 22 artigos foram submetidos à análise da revisão e todos foram subdivididos em três categorias: o paradigma vigente, a ausência de política pública que respalde o parto domiciliar planejado e a lacuna na produção e divulgação do conhecimento. Considerações Finais: Esta revisão aponta como dificuldades do parto domiciliar planejado no Brasil o paradigma vigente, que é tecnocrático, biomédico, intervencionista ou curativista; a ausência de política pública relacionada ao parto domiciliar planejado; e a lacuna na produção e na divulgação do conhecimento específico, com desdobramentos que alcançam a formação de especialistas.
\end{abstract}

Palavras-chave: Enfermagem; Parto Domiciliar; Enfermagem Obstétrica; Cuidados de Enfermagem.

\begin{abstract}
Objective: to describe the difficulties of planned home birth in Brazil evidenced in the scientific production of nursing. Methodology: Systematic review using the descriptors Home Birth; Obstetric Nursing and Nursing Care. The survey of the articles was done in three databases: Scientific Eletronic Library Online (SCiELO), Medical Literature Analysis and Retrievel System Online (Medline) e Literatura Latino-americana e do Caribe em Ciências da Saúde (LILACS), guided by the guided question: What are the difficulties of planned homebirth in Brazil? Studies published from 2010 to March 2021 were included. Results: In total, 22 articles were submitted to review review and all were subdivided into three categories: the current paradigm, the absence of public policy to support planned home birth and the gap in the production and dissemination of knowledge. Final considerations: This review points out the current paradigm, which is technocratic, biomedical, interventionist or curative, as difficulties in planned home births in Brazil; the absence of public policy related to planned home birth; and the gap in the production and dissemination of specific knowledge, with developments that reach the training of specialists.
\end{abstract}

Keywords: Nursing; Homebirth; Obstetric nursing; Nursing care.

\section{Resumen}

Objetivo: describir las dificuldades del parto domiciliario planificado en Brasil evidenciado en la producción científica de enfermería. Metodologia: Revisión sistemática utilizando los descriptores Parto Domiciliario, 
Enfermería Obstétrica y Cuidados de Enfermería. La encuesta de los artículos se realizó en tres bases de datos: Scientific Eletronic Library Online (SCiELO), Medical Literature Analysis and Retrievel System Online (Medline) e Literatura Latino-americana e do Caribe em Ciências da Saúde (LILACS), guiado por la pregunta guiada: ¿Cuáles son las dificuldades del parto domiciliario planificado en Brasil? Se incluyeron estudios publicados de 2010 a marzo de 2021. Resultados: En total, se sometieron a revisión 22 artículos y todos se subdividieron en tres categorías: el paradigma actual, la ausencia de una política pública de apoyo al parto domiciliario planificado y la brecha en la producción y difusión del conocimiento. Consideraciones finales: Esta revisión señala el paradigma actual, tecnocrático, biomédico, intervencionista o curativo, como dificuldades en los partos domiciliarios planificados en Brasil; la ausencia de una política pública relacionada con el parto domiciliario planificado; y la brecha en la producción y difusión de conocimientos específicos, con desarrollos que llegan a la formación de especialistas.

Palabras clave: Enfermería; Parto domiciliario; Enfermería obstétrica; Cuidados de enfermería.

\section{Introdução}

No passado, a mulher tinha seus filhos em casa, assistida pela família ou pela parteira (Seibert, Barbosa, Santos \& Vargem, 2005). Michel Odent (2016), em "Pode a humanidade sobreviver à Medicina?", trata sobre o parto em vários contextos e épocas, até o momento em que o desenvolvimento tecnológico da medicina permitiu o controle médico sobre as leis naturais dos processos humanos de vida. Paradoxalmente, esse controle conduziu a humanidade para uma dependência sem precedentes da tecnologia médica. No contexto brasileiro, particularmente após a década de 60, observou-se um aumentou na quantidade de maternidades hospitalares, porém em algumas regiões distantes dos centros urbanos isso não aconteceu. Nessas regiões mais remotas as parteiras tradicionais permaneceram ativas, ao contrário do que ocorreu nos grandes centros (Feyer et al, 2013; Santos et al, 202). Na segunda metade do século XX os atendimentos hospitalares às brasileiras em trabalho de parto aumentaram rapidamente. Em 2018 os dados do Departamento de Informática do Sistema Único de Saúde (DATASUS) apontaram que $98 \%$ do total de nascimentos ocorreu em hospitais e 0,6\% deste total aconteceram em domicílios (Ministério da Saúde, 2018 como citado em Santos et al, 2021)

O ambiente hospitalar detém aparato tecnológico, porém também tem um histórico de violência obstétrica, iatrogenias e descaso para com o processo parturitivo individual de cada mulher. As notícias sobre os desfechos desfavoráveis evidenciados nos os altos índices de morbimortalidade materno infantil e violências ocorridas em maternidades hospitalares provocaram a mobilização dos movimentos sociais feministas e em saúde, incluindo a Organização Mundial de Saúde (OMS). As mulheres passaram a divulgar a sua insatisfação e necessidade de resgate do entendimento do parto como um evento fisiológico, feminino, familiar e social. Estes movimentos passaram a reivindicar o direito de experienciar o parto como algo prazeroso e humano, impulsionando um início de mudança do modelo tecnocrático vigente, focando na importância da integralidade na atenção à saúde da mulher e do seu bebê. As reivindicações de mudanças alcançaram os profissionais de saúde, em especial as enfermeiras, que também se mobilizaram na busca de uma qualificação que se vinculasse às transformações em curso. Outro desdobramento da pressão social por melhorias na atenção obstétrica se observa na qualificação dos serviços que passou a se relacionar com a conquista do quinto objetivo de desenvolvimento do milênio (ODM): a redução da mortalidade materna e o acesso universal à saúde reprodutiva (Morais, 2011; Prates et al, 2018).

Apesar do paradigma tecnocrático ainda dominar a assistência obstétrica, existe uma resistência que lança luz sobre um entendimento do parto que transcende o evento biológico, e considera as suas características de um processo que também é social, emocional, subjetivo, familiar e cultural. A partir deste entendimento do que seja o processo de parir e nascer, algumas mulheres passaram a escolher mais do que apenas o parto vaginal, mas também a experiência do parto no domicílio. Torna-se então possível tomar esta modalidade de parto como a representação de uma quebra de paradigma no modelo de saúde, que favorece o reconhecimento do protagonismo e do direito de escolha da mulher, com segurança e conforto no processo do parto e nascimento (Lessa et al, 2018; Prates et al, 2018). A partir do exposto acima, emergiu a motivação para compreender as dificuldades do parto domiciliar planejado (PDP) no Brasil, que se direcionou para o estudo que aqui se apresenta. O objetivo 
é descrever as dificuldades do PDP no Brasil evidenciados na produção cientifica de enfermagem. A relevância deste estudo repousa sobre o reconhecimento do PDP como um exercício dos direitos reprodutivos das mulheres que optam pelo ambiente de suas próprias residências como cenário dos seus partos e nascimentos dos seus filhos. Além disso, trata-se de um importante espaço de exercício profissional das enfermeiras obstétricas (EO) autônomas.

\section{Metodologia}

Trata-se de uma revisão sistemática (RS) baseada nos procedimentos recomendados pelo Instituto Joanna Briggs JBI - (JBI, 2014), que se declara interessado no contexto da prestação de cuidados, apoiando a prática baseada em evidências nas áreas de enfermagem, medicina e saúde e afins (Aromataris \& Pearson, 2014). O objetivo da RS é oferecer síntese de uma grande quantidade de pesquisas, num único documento, com garantia de abrangência, transparência e imparcialidade. Desse modo, o conhecimento sintetizado e resumido favorece a tomada de decisão. A metodologia do JBI é indicada para estudos qualitativos experienciais, como este que aqui se apresenta (Munn et al, 2018).

Para o desenvolvimento desta investigação foram utilizados os descritores previamente consultados no Descritores em Ciências da Saúde (DeSC/MeSH): Parto Domiciliar; Enfermagem Obstétrica e Cuidados de Enfermagem. O booleano usado foi o "AND". As bases de dados consultadas foram: Scientific Eletronic Library Online (SCiELO); Medical Literature Analysis and Retrievel System Online (Medline); Literatura Latino-americana e do Caribe em Ciências da Saúde (LILACS). Quanto às interfaces usadas, o acesso à Medline foi feito através da PubMed, e para a LILACS a via foi a Biblioteca Virtual em Saúde (BVS). Os critérios de inclusão empregados foram: artigos disponíveis na íntegra de forma gratuita sobre o parto domiciliar no Brasil, publicados de 2010 a 2021. Os critérios de exclusão foram: a) teses ou dissertações; b) publicações sem metodologia bem descrita; c) artigos de revisão; d) artigos teórico-reflexivos. A busca nas bases de dados ocorreu no dia 30 de março de 2021 e foi repetida em 05 de abril de 2021.

Os 96.492 artigos inicialmente encontrados com os descritores isolados foram agrupados em duplas da seguinte forma: Parto Domiciliar AND Enfermagem Obstétrica; Parto Domiciliar AND Cuidados de Enfermagem; Enfermagem Obstétrica AND Cuidados de Enfermagem. Com isso, foram identificados 474 artigos, conforme apresentado na Tabela 1.

Tabela 1 - Fluxograma de cruzamento dos descritores e seleção nas bases de dados LILACS, MEDLINE e ScieLO. Rio de Janeiro, RJ, Brasil, 2021.

\begin{tabular}{|l|l|l|}
\hline \multicolumn{1}{|c|}{ Bibliotecas } & \multicolumn{1}{|c|}{ Descritores } & Total de títulos \\
\hline \multirow{3}{*}{ LILACS } & Parto Domiciliar AND Enfermagem Obstétrica & 59 \\
\cline { 2 - 3 } & Parto Domiciliar AND Cuidados de Enfermagem & 79 \\
\cline { 2 - 3 } & Enfermagem Obstétrica AND Cuidados de Enfermagem & 238 \\
\hline \multirow{3}{*}{ MEDLINE } & Parto Domiciliar AND Enfermagem Obstétrica & 7 \\
\cline { 2 - 3 } & Parto Domiciliar AND Cuidados de Enfermagem & 17 \\
\cline { 2 - 3 } & Enfermagem Obstétrica AND Cuidados de Enfermagem & 67 \\
\hline \multirow{3}{*}{ SciELO } & Parto Domiciliar AND Enfermagem Obstétrica & 4 \\
\cline { 2 - 3 } & Parto Domiciliar AND Cuidados de Enfermagem & 0 \\
\cline { 2 - 3 } & Enfermagem Obstétrica AND Cuidados de Enfermagem & 3 \\
\hline Total de títulos & & 474 \\
\hline
\end{tabular}

Fonte: Autores (2021).

As informações foram mapeadas de acordo com o modelo do Diagrama de fluxo PRISMA (Preferred Reporting Items for Systematic Reviews and Meta-Analyses) (Moher et al, 2009), conforme demonstrado na Figura 1. Numa primeira análise, 
317 artigos foram eliminados por não atenderem aos critérios de inclusão, restando 157 artigos. Na segunda análise, 36 artigos foram excluídos por serem duplicados, restando 121 publicações. Destas, 90 foram excluídas por não tratarem do PDP e 31 foram selecionadas para análise completa. Por fim, 22 artigos foram selecionados para a presente revisão, os quais foram subdivididos em 3 categorias a partir dos temas abordados por estes. As variáveis analisadas foram qualitativas e envolveram questões relacionadas às mulheres e casais que escolheram o PDP e às enfermeiras que prestam assistência neste contexto, características socioeconômicas e ideológicas dos casais e percepção dos profissionais.

Os resultados indicam as implicações para a política pública, para o cotidiano assistencial e para o desenvolvimento de novas pesquisas. Na etapa final, foram compilados e comunicados os resultados para apresentar a visão geral de todo o material. Foi elaborada uma construção temática organizada de acordo com os elementos que influenciam na resposta da questão norteadora desta pesquisa. E, para a avaliação crítica das produções selecionadas, utilizou-se o sistema de classificação de evidências: N1. Revisão sistemática/metanálises; N2. Estudo clínico randomizado; N3. Ensaios controlados não randomizados; N4. Estudo de coorte ou estudos de caso-controle; N5. Metassíntese de informações qualitativa ou estudos descritivos; N6. Estudos quantitativos únicos ou estudos descritivos e N7. Opinião de especialistas (Lacerda \& Costenaro, 2015; Melnyk \& Fineout-Overholt, 2011).

Os aspectos éticos deste estudo foram preservados e todos os autores dos artigos analisados foram adequadamente referenciados e seu conteúdo apresentado de forma fidedigna, conforme a Lei de Direitos Autorais nº 9.610/98 (Brasil, 1998).

Figura 1. - Fluxograma explicativo da seleção de artigos. Rio de Janeiro/RJ, 2021.

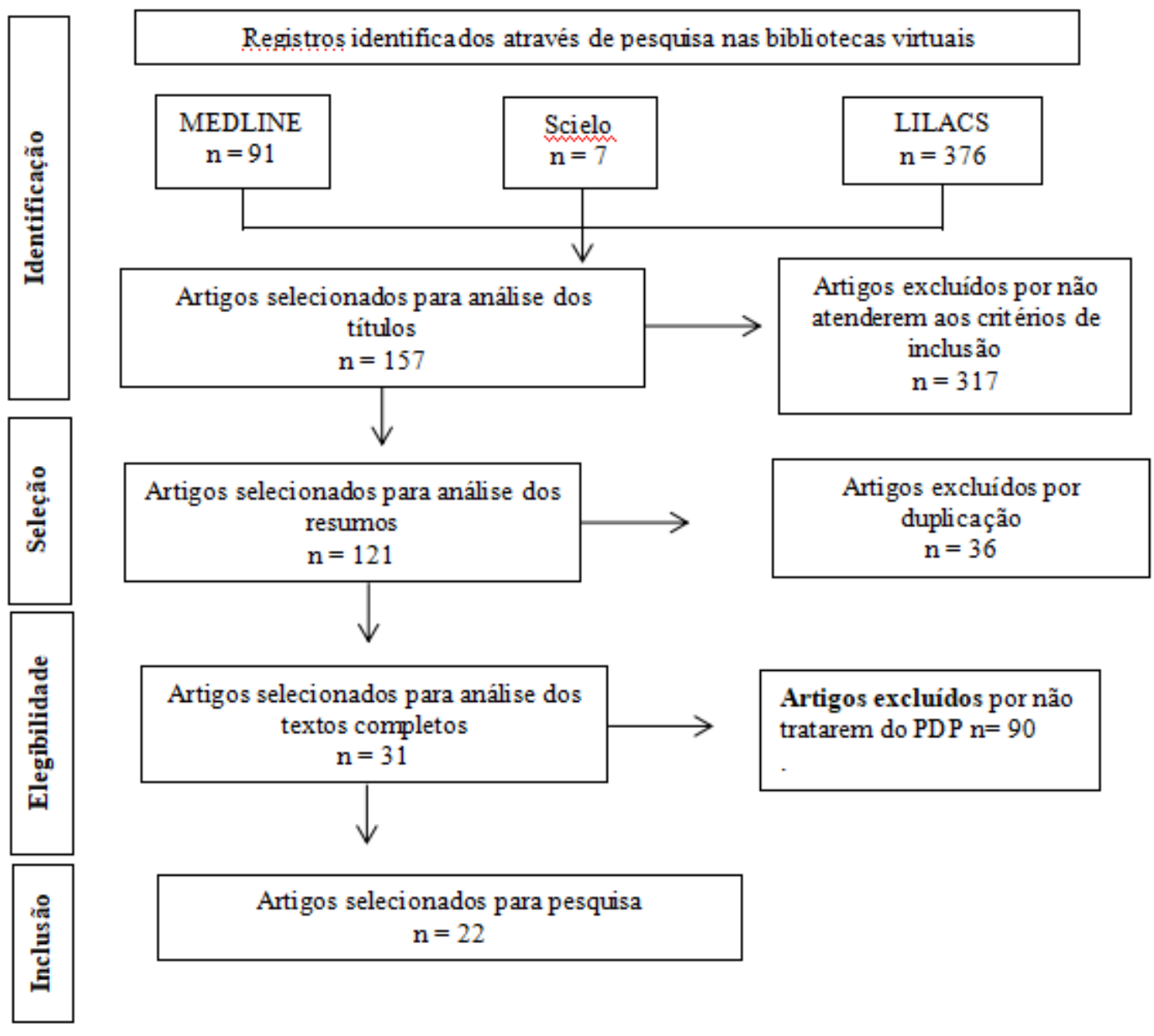

Fonte: Autores (2021). 
A partir da leitura, releitura e análise dos trechos referentes ao tema do estudo, da amostra de 22 artigos emergiram 3 categorias: 1) "O paradigma vigente”, com 11 artigos; 2)

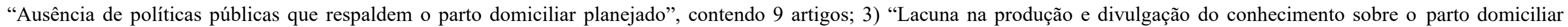

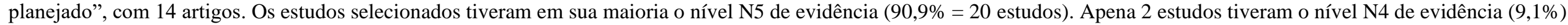

Para favorecer a compreensão, no Quadro 1 são explicitados os conteúdos referentes ao tema do estudo.

Quadro 1. Publicações sobre PDP no Brasil entre 2010 e 2021. Rio de Janeiro, RJ, Brasil, 2021.

\begin{tabular}{|c|c|c|c|c|}
\hline Categoria & Resultados e discussão & Ano & Título & $\begin{array}{l}\text { Nível de } \\
\text { Evidência }\end{array}$ \\
\hline \multirow[t]{3}{*}{$\begin{array}{l}\mathrm{O} \\
\text { paradigma } \\
\text { vigente }\end{array}$} & $\begin{array}{l}\text { "o parto domiciliar ainda é uma prática à margem do sistema convencional de saúde. (...) No contexto } \\
\text { atual, onde o modelo de assistência é predominantemente tecnocrático e baseado em explicações e } \\
\text { procedimentos da racionalidade biomédica, alguns casais enfrentam conflitos familiares para reafirmar a } \\
\text { decisão pelo parto em casa." }\end{array}$ & 2013 & $\begin{array}{l}\text { Rituais de cuidado realizados pelas } \\
\text { famílias na preparação para a } \\
\text { vivência do parto domiciliar } \\
\text { planejado. }\end{array}$ & N5 \\
\hline & $\begin{array}{l}\text { "O evento do parto é visto na atualidade como uma experiência arriscada para a mulher e para o bebê. (...) } \\
\text { o parto no domicílio é tido muitas vezes como um modelo simplificado de assistência e pouco seguro. Os } \\
\text { profissionais apontam algumas críticas de outros profissionais em relação ao acompanhamento no parto } \\
\text { no domicílio. (...) Esta visão de risco e de simplificação pode ser um dos fatores que dificultam a } \\
\text { aceitação mais ampla do parto domiciliar por profissionais e mulheres." }\end{array}$ & 2013 & $\begin{array}{l}\text { A percepção dos profissionais sobre a } \\
\text { assistência ao parto domiciliar } \\
\text { planejado. }\end{array}$ & N5 \\
\hline & $\begin{array}{l}\text { "no Brasil, percebemos que as mulheres que optam pelo parto domiciliar são socialmente reconhecidas } \\
\text { como irresponsáveis, desinformadas e adeptas de um modismo. Da mesma forma, os profissionais que } \\
\text { optam em oferecer esse atendimento estão sendo explicitamente coagidos pelos conselhos de classe, } \\
\text { perseguidos e desmoralizados (...) A recepção institucional nem sempre é realizada de forma acolhedora, } \\
\text { já que a maioria dos profissionais não concorda com o atendimento obstétrico domiciliar, o que gera uma } \\
\text { situação tensa e constrangedora e, algumas vezes, ameaçadora, tanto para as enfermeiras obstetras, quanto } \\
\text { para a parturiente e sua família." }\end{array}$ & 2014 & $\begin{array}{l}\text { Do parto institucionalizado ao parto } \\
\text { domiciliar. }\end{array}$ & N5 \\
\hline
\end{tabular}




\begin{tabular}{|c|c|c|c|}
\hline $\begin{array}{l}\text { "as relações sociais no Brasil confirmam o hospital como único local de parto. (...) As campanhas da } \\
\text { mídia reforçam a importância do profissional médico durante a gestação e no parto." }\end{array}$ & 2014 & $\begin{array}{l}\text { Informação para a opção pelo parto } \\
\text { domiciliar planejado: Um direito de } \\
\text { escolha das mulheres. }\end{array}$ & N5 \\
\hline $\begin{array}{l}\text { "Dentre as mulheres entrevistadas, oito relataram que a família e os amigos expressaram apreensão com } \\
\text { relação à saúde materna-fetal, alguns manifestando que tal opção era loucura, e que exporia a riscos } \\
\text { desnecessários (...) declararam não poder contar para a família e/ou amigos sua opção pelo parto } \\
\text { domiciliar (...) percebe-se como é impactante a reação contrária do círculo social à opção pelo parto } \\
\text { domiciliar. (...) O pensamento dominante é a segurança do parto hospitalar como norma, regra. (...) Diante } \\
\text { de uma cultura tecnocrática nas questões relacionadas ao parto e nascimento, a base dos questionamentos } \\
\text { realizados pela família e pelos amigos, parte da premissa de que o local de parto é o hospital, e quem } \\
\text { assiste ao parto é o médico." }\end{array}$ & 2014 & $\begin{array}{l}\text { Relações sociais na opção pelo parto } \\
\text { domiciliar planejado: um estudo } \\
\text { etnográfico institucional. }\end{array}$ & N5 \\
\hline $\begin{array}{l}\text { "Os casais do estudo buscam e vivem a contracultura do modelo tecnocrático de atenção ao parto, que } \\
\text { perpetua rituais tecnológicos e biologistas no parto, com base em valores que fortalecem a impotência } \\
\text { feminina. (...) O casal, na maioria das vezes, prefere não expor a sua família a decisão em relação ao lugar } \\
\text { onde será o parto, principalmente quando os familiares demonstram resistência ao parto domiciliar, ainda } \\
\text { que seja planejado (...) No contexto brasileiro, o parto domiciliar planejado vive praticamente na } \\
\text { clandestinidade" }\end{array}$ & 2017 & $\begin{array}{l}\text { O significado atribuído pelo casal ao } \\
\text { parto domiciliar planejado, assistido } \\
\text { pelas enfermeiras obstétricas da } \\
\text { Equipe Hanami. }\end{array}$ & N5 \\
\hline "Os relatos registram a superação da cultura da dor, do sofrimento no parto." & 2018 & $\begin{array}{l}\text { A opção pelo parto domiciliar } \\
\text { planejado: uma opção natural e } \\
\text { desmedicalizada. }\end{array}$ & N4 \\
\hline "para alguns grupos, o parto representa um evento dramático, marcado pela dor e pelo sofrimento físico." & 2018 & $\begin{array}{l}\text { Vivências de mulheres com o parto } \\
\text { domiciliar: resgate por meio da } \\
\text { história oral. }\end{array}$ & N5 \\
\hline
\end{tabular}




\begin{tabular}{|c|c|c|c|c|}
\hline & $\begin{array}{l}\text { "Nota-se que o parto domiciliar é percebido como um retrocesso aos antigos moldes de assistência ao } \\
\text { parto conduzido por parteiras tradicionais. Há uma visão de que se está negando às mulheres e aos recém- } \\
\text { nascidos os benefícios dos avanços científicos e tecnológicos que a área da saúde dispõe na atualidade. } \\
\text { Essa visão está relacionada à construção social de que o hospital é o único local possível de parto, o que } \\
\text { resultou em uma espécie de "naturalização" do parto hospitalar, e que parir em casa passou a ser } \\
\text { considerado um evento anormal e prontamente associado à falta de assistência em saúde." }\end{array}$ & 2019 & 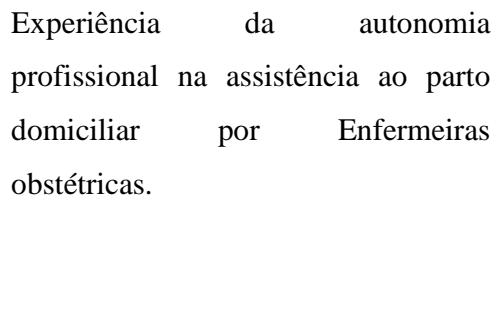 & N5 \\
\hline & $\begin{array}{l}\text { "socialmente, o parto domiciliar planejado é percebido como um retrocesso, por negar às mulheres as } \\
\text { vantagens do progresso da medicina moderna. (...) uma parcela da sociedade reconhece o parto domiciliar } \\
\text { planejado como um ato de irresponsabilidade e de risco para o binômio, uma vez que as participantes } \\
\text { referem ser vítimas de estereótipos e culpabilizações diante de qualquer situação que envolva o parto } \\
\text { domiciliar (...) Este cenário reforça a cultura de parto como hospitalar e superestima a segurança que } \\
\text { proporciona (...) algumas famílias, por medo do julgamento, preferem não socializar a decisão sobre o } \\
\text { parto domiciliar." }\end{array}$ & 2020 & $\begin{array}{l}\text { Dificuldades da assistência ao parto } \\
\text { domiciliar na ótica de enfermeiras } \\
\text { obstetras. }\end{array}$ & N5 \\
\hline & $\begin{array}{l}\text { "a rede de apoio familiar e a profissional. A primeira, na maioria das vezes, condena ou estereotipa o } \\
\text { parto domiciliar como uma ação inadequada pelos riscos que pode oferecer à parturiente e ao bebê, } \\
\text { diferentemente do hospital. Na segunda rede, as gestantes encontram profissionais da área da Saúde que } \\
\text { ainda são desfavoráveis ao parto domiciliar e, por isso, a desaconselham (...) dentre as forças que se opõe } \\
\text { ao parto domiciliar, o paradigma curativista, que tem no médico sua figura principal e prevalece tanto } \\
\text { entre as gestantes quanto entre os próprios profissionais da área da Saúde, integrantes das equipes } \\
\text { multidisciplinares." }\end{array}$ & 2020 & $\begin{array}{l}\text { Desafios enfrentados por enfermeiros } \\
\text { obstetras para a promoção do parto } \\
\text { domiciliar na contemporaneidade. }\end{array}$ & N5 \\
\hline $\begin{array}{l}\text { Ausência } \\
\text { de política } \\
\text { pública que } \\
\text { respalde o } \\
\text { parto }\end{array}$ & $\begin{array}{l}\text { "Todas as transferências ocorreram no primeiro período clínico do parto (...) Esse fato pode ser decorrente } \\
\text { da inexistência de um sistema formal de referência e contrarreferência para esse tipo de assistência no } \\
\text { Brasil, o que determina a transferência precoce para minimizar eventuais riscos maternos e fetais." }\end{array}$ & 2012 & $\begin{array}{l}\text { Partos domiciliares planejados } \\
\text { assistidos por enfermeiras obstétricas: } \\
\text { transferências maternas e neonatais. }\end{array}$ & N5 \\
\hline
\end{tabular}


Research, Society and Development, v. 10, n. 7, e45910716540, 2021

(CC BY 4.0) | ISSN 2525-3409 | DOI: http://dx.doi.org/10.33448/rsd-v10i7.16540

\begin{tabular}{|c|c|c|c|c|}
\hline \multirow[t]{6}{*}{$\begin{array}{l}\text { domiciliar } \\
\text { planejado }\end{array}$} & $\begin{array}{l}\text { "as pessoas que optam pelo parto domiciliar, nos grandes centros urbanos, têm acesso à informação e } \\
\text { possuem alto nível de instrução acadêmica, o que possivelmente lhes garante uma rentabilidade que } \\
\text { possibilita a contração do serviço particular na assistência ao parto domiciliar, uma vez que o Sistema } \\
\text { Único de Saúde brasileiro (SUS) não subsidia tal opção" }\end{array}$ & 2013 & $\begin{array}{l}\text { Perfil de casais que optam pelo parto } \\
\text { domiciliar assistido por enfermeiras } \\
\text { obstétricas. }\end{array}$ & N5 \\
\hline & $\begin{array}{l}\text { "A busca pela informação levou, na prática, à possibilidade da opção, uma opção indisponível para a } \\
\text { população em geral, já que o Sistema Único de Saúde (SUS) não oferece esta modalidade de assistência." }\end{array}$ & 2014 & $\begin{array}{l}\text { Informação para a opção pelo parto } \\
\text { domiciliar Planejado: Um direito de } \\
\text { escolha das mulheres. }\end{array}$ & N5 \\
\hline & $\begin{array}{l}\text { "características sociodemográficas podem ter facilitado a escolha, uma vez que, atualmente no Brasil, o } \\
\text { atendimento ao parto domiciliar exige um planejamento financeiro." }\end{array}$ & 2015 & $\begin{array}{l}\text { Comparação de resultados obstétricos } \\
\text { e neonatais entre Primíparas e } \\
\text { multíparas assistidas no domicílio. }\end{array}$ & N4 \\
\hline & $\begin{array}{l}\text { "as mulheres, homens e casais que optam por esta alternativa, precisam bancar financeira e } \\
\text { emocionalmente sua escolha. O que fragiliza muito a assistência à mulher, sua família e aos profissionais } \\
\text { que estão lhe prestando cuidados é o fato de que ainda o parto domiciliar planejado não esteja } \\
\text { contemplado nas políticas públicas de saúde e que o sistema de referência e contrarreferência, } \\
\text { consequentemente, não funciona. A ausência do Ministério da Saúde no debate sobre o direito de escolha } \\
\text { do local de parto provoca isolamento das mulheres." }\end{array}$ & 2017 & $\begin{array}{l}\text { O significado atribuído pelo casal ao } \\
\text { parto domiciliar planejado, assistido } \\
\text { pelas enfermeiras obstétricas da } \\
\text { Equipe Hanami. }\end{array}$ & N5 \\
\hline & $\begin{array}{l}\text { "No Brasil, há apenas um pequeno número de atendimentos de partos domiciliares pelo Sistema Único de } \\
\text { Saúde (SUS), pela equipe do Hospital Sofia Feldman." }\end{array}$ & 2017 & $\begin{array}{l}\text { Resultados maternos dos partos } \\
\text { domiciliares planejados assistidos por } \\
\text { enfermeiras da equipe Hanami no Sul } \\
\text { do Brasil, 2002-2012. }\end{array}$ & N5 \\
\hline & $\begin{array}{l}\text { "Numa sociedade em que o parto domiciliar planejado ainda não é uma política pública, a opção por parir } \\
\text { no domicílio é construída a partir das relações sociais." }\end{array}$ & 2018 & $\begin{array}{l}\text { A opção pelo parto domiciliar } \\
\text { planejado: uma opção natural e } \\
\text { desmedicalizada. }\end{array}$ & N4 \\
\hline
\end{tabular}




\begin{tabular}{|c|c|c|c|c|}
\hline & $\begin{array}{l}\text { "No Brasil, inexiste um protocolo para o atendimento no domicílio, assim, as equipes decidem incluir ou } \\
\text { não mulheres com cesárea prévia no seu protocolo de atendimento e qual o intervalo interpartal." }\end{array}$ & 2018 & $\begin{array}{l}\text { Práticas obstétricas nos partos } \\
\text { domiciliares planejados assistidos no } \\
\text { Brasil. }\end{array}$ & N5 \\
\hline & $\begin{array}{l}\text { "Os discursos (...) retratam a situação de transferência para o hospital como um grande entrave vivenciado } \\
\text { pelas enfermeiras obstetras dentro do processo de trabalho da assistência ao parto em domicílio. (...) } \\
\text { ausência de: serviço que realize exames laboratoriais solicitados pelas enfermeiras obstetras durante o } \\
\text { acompanhamento pré-natal ou puerperal; local que permita a compra de insumos básicos (medicações) } \\
\text { para uso em ambiente domiciliar pela enfermeira obstetra; e diretrizes/protocolos que direcionem a } \\
\text { atuação das enfermeiras obstétricas de forma homogênea." }\end{array}$ & 2020 & $\begin{array}{l}\text { Dificuldades da assistência ao parto } \\
\text { domiciliar na ótica de enfermeiras } \\
\text { obstetras. }\end{array}$ & N5 \\
\hline \multirow{3}{*}{$\begin{array}{l}\text { Há uma } \\
\text { lacuna na } \\
\text { produção e } \\
\text { divulgação } \\
\text { do } \\
\text { conhecime } \\
\text { nto sobre o } \\
\text { parto } \\
\text { domiciliar } \\
\text { planejado }\end{array}$} & "há poucos dados publicados sobre esse tipo de assistência no Brasil." & 2012 & $\begin{array}{l}\text { Resultado de partos domiciliares } \\
\text { atendidos por enfermeiras de } 2005 \text { a } \\
2009 \text { em Florianópolis, SC. }\end{array}$ & N5 \\
\hline & $\begin{array}{l}\text { "vivenciamos diariamente todas as dificuldades que surgem quando mergulhamos em um campo de } \\
\text { atuação tão pouco explorado. (...) O parto domiciliar, em nossa realidade, ainda é visto com muito } \\
\text { preconceito por grande parte de nossa sociedade, principalmente devido à divulgação de conceitos } \\
\text { equivocados sobre o tema." }\end{array}$ & 2014 & $\begin{array}{l}\text { Do parto institucionalizado ao parto } \\
\text { domiciliar. }\end{array}$ & N4 \\
\hline & $\begin{array}{l}\text { "na maioria das vezes, as mulheres delegam o poder ao profissional ou simplesmente aceitam o } \\
\text { conhecimento dele como indiscutível, por não terem acesso a dados que lhes permitam questionar o saber } \\
\text { científico do especialista. (...) A maioria das mulheres da cidade do Rio de Janeiro não imagina a } \\
\text { possibilidade de um parto não hospitalar, isto porque essa informação não está disponível nos serviços de } \\
\text { saúde; por sua vez, elas não buscam esta informação. Nos textos e formulários aos quais as mulheres têm } \\
\text { acesso, como o cartão da gestante, não existe referência à possibilidade de opção relativa ao local e ao } \\
\text { profissional que assiste ao parto nos serviços de saúde públicos ou privados." }\end{array}$ & 2014 & $\begin{array}{l}\text { Informação para a opção pelo parto } \\
\text { domiciliar planejado: Um direito de } \\
\text { escolha das mulheres. }\end{array}$ & N5 \\
\hline
\end{tabular}




\begin{tabular}{|c|c|c|c|}
\hline $\begin{array}{l}\text { "Desse modo, a cultura pró-cesariana remete segurança para a família e o medo está sustentado pela } \\
\text { escassez de conhecimento." }\end{array}$ & 2014 & $\begin{array}{l}\text { Relações sociais na opção pelo parto } \\
\text { domiciliar planejado: um estudo } \\
\text { etnográfico institucional. }\end{array}$ & N5 \\
\hline $\begin{array}{l}\text { "Escolhas e decisões da mulher quanto ao tipo de parto são decorrentes de um processo que envolve } \\
\text { múltiplos fatores, tais como escolaridade, condições socioeconômicas, história de vida, histórias de parto } \\
\text { que ouviu ou viveu, conhecimento sobre as condições de assistência ao parto e acesso às informações, } \\
\text { geralmente inacessíveis para a grande parte das mulheres." }\end{array}$ & 2015 & $\begin{array}{l}\text { Parto domiciliar: compreendendo os } \\
\text { motivos dessa escolha. }\end{array}$ & N5 \\
\hline $\begin{array}{l}\text { "falta de informação e orientaçães para a maioria das mulheres, o que contribui para que a escolha do } \\
\text { local de parto possa ser feita apenas por aquelas com maior poder econômico, o que gera exclusão social. } \\
\text { (...) É limitação desse estudo a reduzida produção científica nesta área. Talvez seja um dos fatores para } \\
\text { maior sedimentação desta prática. Além disto, identifica-se a necessidade de problematizar esta situação } \\
\text { junto às entidades profissionais, especialmente àquelas que congregam médicos, bem como a inclusão } \\
\text { deste tema na formação dos profissionais de saúde.” }\end{array}$ & 2017 & $\begin{array}{l}\text { O significado atribuído pelo casal ao } \\
\text { parto domiciliar planejado, assistido } \\
\text { pelas enfermeiras obstétricas da } \\
\text { Equipe Hanami. }\end{array}$ & N5 \\
\hline $\begin{array}{l}\text { "escassa publicação de dados nacionais quantitativos sobre a assistência no domicílio para comparar os } \\
\text { resultados obtidos." }\end{array}$ & 2017 & $\begin{array}{l}\text { Resultados maternos dos partos } \\
\text { domiciliares planejados assistidos por } \\
\text { enfermeiras da equipe Hanami no Sul } \\
\text { do Brasil, 2002-2012. }\end{array}$ & N5 \\
\hline $\begin{array}{l}\text { "A falta de orientação e de conhecimento por parte das mulheres e dos profissionais de saúde habilitados } \\
\text { ao trabalho de parto referente às diversas técnicas não farmacológicas de alívio da dor sustenta os mitos } \\
\text { da dor insuportável no processo de parir no cotidiano." }\end{array}$ & 2018 & $\begin{array}{l}\text { A opção pelo parto domiciliar } \\
\text { planejado: uma opção natural e } \\
\text { desmedicalizada. }\end{array}$ & N4 \\
\hline "ao perscrutar a literatura evidenciou-se que o tema ainda é pouco investigado no país." & 2019 & $\begin{array}{l}\text { Atuação do enfermeiro obstetra no } \\
\text { parto domiciliar planejado. }\end{array}$ & N5 \\
\hline
\end{tabular}




\begin{tabular}{|c|c|c|c|}
\hline $\begin{array}{l}\text { "Com base nesse contexto de assistência precária e com poucos recursos materiais e tecnológicos, aliado } \\
\text { ao imaginário das pessoas, em que o parto ideal é representado pelo parto hospitalar, rodeado de } \\
\text { tecnologias, muitas pessoas demonstraram preconceito e desconhecimento sobre como ocorre a } \\
\text { assistência ao parto domiciliar no atual modelo." }\end{array}$ & 2019 & $\begin{array}{l}\text { Experiência } \text { da } \\
\text { profissional na } \\
\text { domiciliar } \\
\text { por }\end{array}$ & N5 \\
\hline $\begin{array}{l}\text { "as enfermeiras obstetras enfrentavam preconceito por diversas camadas da sociedade em relação à } \\
\text { assistência ao parto prestada no domicílio, devido à falta de informações sobre este modelo de } \\
\text { assistência." }\end{array}$ & 2020 & $\begin{array}{l}\text { Dificuldades da assistência ao parto } \\
\text { domiciliar na ótica de enfermeiras } \\
\text { obstetras. }\end{array}$ & N5 \\
\hline $\begin{array}{l}\text { "Antigamente, o parto era visualizado como um evento familiar, onde parteiras eram formadas de } \\
\text { gerações e realizavam os partos de forma empírica, levando muitas mulheres e bebês a falecerem por falta } \\
\text { de assistência, afirmando a falsa ideia de que hoje a realidade é a mesma (...) os desafios enfrentados por } \\
\text { enfermeiros obstetras para promover o parto domiciliar estão relacionados à dificuldade de acesso a } \\
\text { informações seguras ou até mesmo_ausência delas.” }\end{array}$ & 2020 & $\begin{array}{l}\text { Desafios enfrentados por enfermeiros } \\
\text { obstetras para a promoção do parto } \\
\text { domiciliar na contemporaneidade. }\end{array}$ & N5 \\
\hline $\begin{array}{l}\text { "faz-se necessário ampliar a grade curricular na formação profissional, principalmente dos cursos de Pós- } \\
\text { Graduação, considerando as experiências das enfermeiras obstétricas que atuam no PDP e dos protocolos } \\
\text { internacionais para o atendimento do parto domiciliar, sendo então melhor explorados." }\end{array}$ & 2020 & $\begin{array}{l}\text { Assistência ao parto domiciliar } \\
\text { planejado: Trajetória profissional } \\
\text { e especificidades do cuidado da } \\
\text { enfermeira obstétrica. }\end{array}$ & N5 \\
\hline $\begin{array}{l}\text { "O ensino dentro da residência foca nas políticas de saúde vigentes, embora, no caso do parto domiciliar } \\
\text { planejado, não exista no Brasil uma política específica para este serviço. Logo, as residências do país } \\
\text { provavelmente não têm formado EO para este campo. (...) O mesmo deve acontecer com as } \\
\text { especializações, as quais também visam à formação dentro do espectro das políticas nacionais de atenção } \\
\text { ao parto e nascimento, que é predominantemente hospitalar." }\end{array}$ & 2021 & $\begin{array}{l}\text { Trajetórias de enfermeiras obstetras } \\
\text { no atendimento ao parto domiciliar } \\
\text { planejado: história oral. }\end{array}$ & N5 \\
\hline
\end{tabular}

Fonte: Autores (2021). 


\section{Discussão}

\section{O paradigma vigente}

Dos estudos que compõem esta categoria, oito chamam o paradigma obstétrico vigente de tecnocrático, biomédico, intervencionista ou curativista. Cinco artigos apontam o PDP como uma assistência simples ou arriscada, além de considerá-la um retrocesso quando comparada à assistência segura que se vincula ao parto hospitalar. Também nesta categoria, três estudos apontam a centralidade do médico como profissional ideal para assistir o parto, ou o hospital como ambiente seguro de assistência. Três artigos mostram que os casais preferem não socializar a opção pelo PDP para evitarem o preconceito que envolve tal escolha. Dois artigos trazem relatos de famílias que foram consideradas irresponsáveis por terem optado pelo PDP. A dor também parece ser relevante na ideia do que seja um PDP, conforme indicam dois artigos. Além das questões sociais gerais, dois artigos indicam que há também desaprovação do PDP e aconselhamento do parto hospitalar por parte de profissionais que não são enfermeiras obstétricas. Um artigo indica que o PDP é considerado clandestino.

Os resultados do estudo que aqui se apresenta confirmam que no Brasil o parto ainda é centrado no médico e no ambiente hospitalar (Collaço et al, 2017; Feyer et al, 2013; Souza et al, 2020), sendo o rompimento com o modelo vigente de parto um desafio, tanto para as gestantes quanto para as enfermeiras obstétricas. Tal fato se mostra nos círculos sociais dos casais que optam pelo PDP, que demonstram muita resistência a essa escolha. Os argumentos são fortes e estão baseados na ideia, desprovida de qualidade nas informações, de que o ambiente doméstico expõe a mulher e o bebê a riscos desnecessários, sendo considerado um retrocesso e/ou uma prática clandestina. Assim, os casais temem confrontar o paradigma vigente, tanto no âmbito familiar quanto nos espaços de convívio social (Lessa et al, 2014a; Pascoto et al, 2020; Sanfelice et al, 2014).

Também percebe-se que ainda há o desafio de enfrentar o discurso de profissionais de saúde, que supostamente conhecem a temática e, apropriados da autoridade que lhes é socialmente conferida, aconselham o abandono da ideia de um parto no domicílio, recomendando o parto hospitalar por ser considerado superior em segurança, menos doloroso e mais apropriado ao tempo em que vivemos (Feyer, Monticelli \& Knobel, 2013a; Pascoto et al, 2020; Serres et al, 2018; Souza et al, 2020).

\section{Ausência de política pública que respalde o parto domiciliar planejado}

Nesta categoria quatro artigos destacam que o SUS não abarca o PDP, ou que não há políticas públicas que o contemplem. Outro tema que se destacou, sendo representada por três artigos, foi a ausência de um sistema de referência e contrarreferência, afetando a transferência hospitalar. A família precisa realizar um planejamento financeiro para o PDP, segundo indicam dois artigos. Em dois artigos o destaque está na ausência de protocolos para atendimento ao PDP. Sobre a atenção ao PDP feita a partir de uma instituição pública há um artigo. Há também um artigo que indica a inexistência de serviços que possam ser usados por EO que atendem PDP.

No contexto brasileiro, muitos estudos indicam que o SUS não abarca o atendimento ao PDP, com ausência de políticas públicas que respaldem esse modelo de assistência obstétrica (Collaço et al, 2017; Koettker et al, 2017; Pascoto et al, 2020), ainda que exista um pequeno número de PDP atendidos pelo sistema público de saúde, representado pelo Hospital Sofia Feldman (Oliveira et al, 2020). Diante dos resultados obtidos, percebe-se também que essa ausência de políticas públicas direcionadas ao modelo de PDP desencadeia a falta de diretrizes que orientem a prática profissional em domicílio, com protocolos criados de acordo com cada equipe profissional. Os resultados explicitam também que há um menor número de PDP quando comparados aos partos institucionalizados porque, apesar de o SUS indicar o direito da mulher à escolha do ambiente de parto (Pascoto et al, 2020; Volpato et al, 2020), a ausência de políticas públicas faz com que apenas casais com alto poder aquisitivo tenham o direito a essa modalidade de parto assegurado (Koettker et al 2015; Souza et al, 2020). 
Outro tema que emergiu nessa categoria foi o da falta de integração entre o serviço de assistência obstétrica no domicílio com os serviços públicos de saúde. Sem contar com a possibilidade de um sistema integrado, ocorrem dificuldades nas situações de necessidade de transferência, da mulher ou do bebê, para um hospital. Existem diversos relatos, tanto de EO quanto de mulheres, sobre o modo como são recepcionadas nessas situações: ameaças, retaliações, culpabilizações e tratamento hostil por parte da equipe de saúde do hospital. É notória a falta de posturas éticas e respeitosas por parte das equipes hospitalares, mas também da ausência de políticas públicas (Koettker et al, 2012; Pascoto et al, 2020).

\section{Há uma lacuna na produção e divulgação do conhecimento sobre o parto domiciliar planejado}

Nesta categoria quatro artigos mostram a insuficiência dos dados publicados sobre PDP. Além disso, quatro artigos indicam que há falta de conhecimento acerca do PDP, enquanto dois artigos revelam a associação negativa que é feita entre o PDP e as parteiras tradicionais. Aqui também estão dois artigos que destacam a formação deficitária de especialistas no campo do PDP. A escassa quantidade de publicações com dados nacionais acerca do PDP se reflete no esclarecimento e na divulgação da assistência nesse desse modelo. O resultado é a baixa socialização da prática obstétrica domiciliar (Collaço et al, 2017; Souza et al, 2020; Koettker et al, 2017). Outro dado interessante é o efeito provocado pela falta de conhecimento, que se reflete no imaginário social, a partir de profissionais de saúde e entre eles. A consequência direta é a disseminação de uma falsa ideia sobre a assistência prestada pelas EO no PDP, colocando-a como idêntica àquela prestada por parteiras tradicionais. Não se questiona a qualidade do trabalho realizado pelas parteiras tradicionais, mas a ideia que povoa o imaginário popular associando-as ao empirismo e aos desfechos negativos supostamente frequentes (Silva et al, 2019).

$\mathrm{O}$ cuidado à mulher que escolhe o PDP enfrenta não somente desafios relacionados à carência de estudos e de divulgação social, há também um desafio no campo acadêmico, a abordagem deste modelo nos programas voltados para a formação de especialistas. O escopo destes programas, em geral, se volta para a rede que integra os serviços de saúde que compõem o SUS. Neles, provavelmente, a temática do cuidado de Enfermagem Obstétrica voltado para a mulher que decide dar à luz em casa não recebe destaque nas discussões e práticas. A consequência direta é o perfil das egressas dos Cursos de Especialização em Enfermagem Obstétrica e dos Cursos de Especialização em Enfermagem Obstétrica na modalidade de Residência, instrumentalizadas para atuar na atenção em saúde hospitalar e na interdisciplinaridade articulada e mediada pelo SUS e demais políticas setoriais que não contemplam o PDP (Oliveira et al, 2020).

\section{Considerações Finais}

De acordo com os resultados deste estudo, foi possível perceber que há necessidade de superação do modelo obstétrico vigente e de mudança da mentalidade dos profissionais de saúde, que desconhecem os dados nacionais e internacionais referentes ao PDP. Tal fato desencadeia a socialização de atitudes preconceituosas, além de informações equivocadas e carregadas de preconceito. O sistema público de saúde do Brasil deve reconhecer o PDP como uma possibilidade de cuidado na atenção obstétrica a ser ofertada por meio de Políticas Públicas que respaldem a sua prática. Este modelo de assistência ao parto precisa ganhar notoriedade social e, consequentemente, gerar aumento do número de estudos sobre ele. A escolha do local do parto é um direito de todas as mulheres brasileiras independentemente da sua posição na sociedade.

Outro desafio encontrado está vinculado à própria formação das especialistas em Enfermagem Obstétrica, que confere vulnerabilidade no que se refere à competência e à habilidade técnica necessárias para o atendimento ao PDP. Tal fato tem como consequência a escassez de recursos humanos que atendam a demanda das mulheres que escolhem os seus domicílios como ambiente de parto. Além disso, há uma lacuna na quantidade e na qualidade das fontes de dados relacionados ao modelo 
de assistência do PDP, o que impulsiona a difusão de informações de baixa qualidade por parte, tanto dos profissionais de saúde, quanto pela sociedade em geral, sendo necessário que mais estudos sejam realizados a fim de consolidar e disseminar dados nacionais acerca do PDP.

A presente pesquisa apresentou uma limitação importante quanto ao reduzido tamanho da sua amostra e o seu nível de evidência das publicações selecionadas. A contribuição deste estudo se verifica na importância de uma ampliação nas modalidades de formação de profissionais de saúde que contemple o modelo do PDP. Outra contribuição é a participação desta pesquisa como um elemento que se soma aos esforços da Enfermagem Obstétrica para garantir a escolha da própria casa para parir. E como contribuição final apontamos a gravidade de uma situação em que um direito de escolha das mulheres não encontra respaldo nas Políticas Públicas do Brasil, limitando o acesso a esse modelo de assistência obstétrica. Nesse sentido, considerando os resultados dessa pesquisa, sugerimos que mais estudos sejam realizados, tanto com abordagem quantitativa quanto qualitativa, com o fim de consolidar e disseminar dados nacionais acerca do PDP.

\section{Referências}

Aromataris E., \& Pearson A. The systematic review: an overview. Am J Nurs. 2014 Mar;114(3):53-8. https://pubmed.ncbi.nlm.nih.gov/24572533/

Bochnia, E. R., Maneira, N., Trigueiro, T. H., Favero, L., Kochla, K. R. A., \& Oliveira, F. A. M. D. (2019). Atuação do enfermeiro obstetra no parto domiciliar planejado. Ciênc. cuid. saúde, 8-8.

Brasil, A. B. (1998). Direitos autorais. Imprensa Nacional.

Collaço, V. S., Santos, E. K. A. D., Souza, K. V. D., Alves, H. V., Zampieri, M. D. F., \& Gregório, V. R. P. (2017). O significado atribuido pelo casal ao parto domiciliar planejado, assistido pelas enfermeiras obstétricas da Equipe Hanami. Texto Contexto Enferm, $26(2)$, e6030015.

Feyer, I. S. S., Monticelli, M., Boehs, A. E., \& Santos, E. K. A. D. (2013). Rituales de cuidado realizados por las familias en la preparación para la experiencia del parto domiciliario planeado. Revista Brasileira de Enfermagem, 66(6), 879-886.

Feyer, I. S. S., Monticelli, M., \& Knobel, R. (2013a). Perfil de casais que optam pelo parto domiciliar assistido por enfermeiras obstétricas. Escola Anna Nery, $17(2), 298-305$

Frank, T. C., \& Pelloso, S. M. (2013). A percepção dos profissionais sobre a assistência ao parto domiciliar planejado. Revista Gaúcha de Enfermagem, 34(1), 22-29.

Institute TJB. Joanna Briggs Institute Reviewers' Manual: 2014 Edition. [Internet]. Adelaide: Joanna Briggs Institute; 2014. http://joannabriggs.org/assets/docs/sumari/ReviewersManual-2014.pdf

Koettker, J. G., Brüggemann, O. M., \& Dufloth, R. M. (2013). Partos domiciliares planejados assistidos por enfermeiras obstétricas: transferências maternas e neonatais. Revista da Escola de Enfermagem da USP, 47(1), 15-21

Koettker, J. G., Bruggemann, O. M., Freita, P. F., Riesco, M. L. G., \& Costa, R. (2018). Práticas obstétricas nos partos domiciliares planejados assistidos no Brasil. Revista da Escola de Enfermagem da USP, 52.

Koettker, J. G., Brüggemann, O. M., Düfloth, R. M., Knobel, R., \& Monticelli, M. (2012). Resultado de partos domiciliares atendidos por enfermeiras de 2005 a 2009 em Florianópolis, SC. Revista de Saúde Pública, 46(4).

Koettker, J. G., Brüggemann, O. M., Düfloth, R. M., Monticelli, M., \& Knobel, R. (2015). Comparação de resultados obstétricos e neonatais entre primíparas e multíparas assistidas no domicílio. Ciencia y enfermería, 21(2), 113-125.

Koettker, J. G., Brüggemann, O. M., \& Knobel, R. (2017). Resultados maternos dos partos domiciliares planejados assistidos por enfermeiras da equipe hanami no sul do Brasil, 2002-2012. Texto \& Contexto-Enfermagem, 26(1).

Lacerda, M. R., Costenaro, R. G. S. (2015). Metodologias da pesquisa para a enfermagem e saúde: da teoria à prática/organizadoras. Porto Alegre: Moriá.

Lessa, H. F., Tyrrell, M. A. R., Alves, V. H., \& Rodrigues, D. P. (2014). Informação para a opção pelo parto domiciliar planejado: um direito de escolha das mulheres. Texto \& Contexto-Enfermagem, 23(3), 665-672.

Lessa, H. F., Tyrrell, M. A. R., Alves, V. H., \& Rodrigues, D. P. (2014). Relações sociais na opção pelo parto domiciliar planejado: um estudo etnográfico institucional. Online Brazilian Journal of Nursing, 13(2), 239-249.

Lessa, H. F., Tyrrell, M. A. R., Alves, V. H., \& Rodrigues, D. P. (2018). Choosing the home planned childbirth: a natural and drug-free option/A opção pelo parto domiciliar planejado: uma opção natural e desmedicalizada. Revista de Pesquisa: Cuidado é Fundamental Online, 10(4), $1118-1122$. 
Research, Society and Development, v. 10, n. 7, e45910716540, 2021

(CC BY 4.0) | ISSN 2525-3409 | DOI: http://dx.doi.org/10.33448/rsd-v10i7.16540

Melnyk, B. M. \& Fineout-Overholt, E. (Eds.). (2011). Evidence-based practice in nursing \& healthcare: A guide to best practice. Lippincott Williams \& Wilkins.

Moher D, Liberati A, Tetzlaff J, Altman D. G., PRISMA Group. Preferred reporting items for systematic reviews and meta-analyses: the PRISMA statement. PLoS Med 2009; 6(7):e1000097. https://journals.plos.org/plosmedicine/article?id=10.1371/journal.pmed.1000097

Morais, F. R. C. (2011). Interface da sexualidade no processo de parturição: perspectiva de mulheres.

Munn, Z., Stern, C., Aromataris, E., Lockwood, C., \& Jordan, Z. (2018). What kind of systematic review should I conduct? A proposed typology and guidance for systematic reviewers in the medical and health sciences. BMC medical research methodology, 18(1), 5. https://bmcmedresmethodol.biomedcentral.com/articles/10.1186/s12874-017-0468-4

Odent, M. (2016). Pode a humanidade sobreviver à medicina. Tradução de Izabel Aleixo Laura Uplinger, 1.

Oliveira, T. R., Barbosa, A. F., Alves, V. H., Rodrigues, D. P., Dulfe, P. A. M., \& Maciel, V. L. (2020). Assistência ao parto domiciliar planejado: Trajetória profissional e especificidades do cuidado da enfermeira obstétrica. Texto \& Contexto-Enfermagem, 29.

Pascoto, G. D. S., Tanaka, E. Z., Fernandes, L. C. R., Shimo, A. K. K., \& Sanfelice, C. F. D. O. (2020). Dificuldades da assistência ao parto domiciliar na ótica de enfermeiras obstetras. Rev. baiana enferm, e36633-e36633.

Prates, L. A., Simões Timm, M., Antunes Wilhelm, L., Cremonese, L., Oliveira, G., Schimith, M. D., \& Ressel, L. B. (2018). Natural nascer em casa: rituais de cuidado para o parto domiciliar. Revista Brasileira de Enfermagem, 71.

Sanfelice, C. F. D. O., Abbud, F. D. S. F., Pregnolatto, O. S., da Silva, M. G., \& Shimo, A. K. K. (2014). Do parto institucionalizado ao parto domiciliar From institutionalized birth to home birth. Revista da Rede de Enfermagem do Nordeste, 15(2), 362-370.

Sanfelice, C. F. D. O., \& Shimo, A. K. K. (2015). Parto domiciliar: compreendendo os motivos dessa escolha. Texto \& Contexto-Enfermagem, 24(3), 875-882.

Santos, L. M., Mata, J. A. L. D., Vaccari, A., \& Sanfelice, C. F. D. O. (2021). Trajetórias de enfermeiras obstetras no atendimento ao parto domiciliar planejado: história oral. Revista Gaúcha de Enfermagem, 42(SPE).

Seibert, S. L., Barbosa, J. L. D. S., Santos, J. M. D., \& Vargens, O. M. D. C. (2005). Medicalização x humanização: o cuidado ao parto na história. Rev. enferm. UERJ, 245-251.

Serres, W. P., Pieszak, G. M., Gomes, G. C., Prates, L. A., \& Rodrigues, A. P. (2020). Vivências de mulheres com o parto domiciliar: resgate por meio da história oral. Revista de Enfermagem da UFSM, 10, 51.

Silva, E. O. D., de Lima Sanches, M. E. T., Santos, A. A. P., \& de Amorim Barros, L. (2019). Experiência da autonomia profissional na assistência ao parto domiciliar por enfermeiras obstétricas. Revista Baiana de Enfermagem33,

Souza, N. R.D., Lacerda, G. D. S. C., Silva, M. A., Carneiro, A. L. M., de Almeida, C. S., Cecilio, S. G., \& Souza, D. A. S. (2020). Desafios enfrentados por enfermeiros obstetras para a promoção do parto domiciliar na contemporaneidade. Nursing (São Paulo), 23(268), 4654-4665.

Volpato, F., Costa, R., de Lima, M. M., Verdi, M. I. M., Gomes, I. E. M., \& Scapin, S. Q. (2020). Parto domiciliar planejado no contexto da covid19: informações para a tomada de decisão. 